\title{
The European Conceptual History Project (ECHP): Mission Statement
}

After a complex integration process which has taken more than half a century, most Europeans-and non-Europeans-no longer identify Europe with simply an economic common market; yet the final political status of the European Union is still an open question. In general, Europe is usually regarded as the birthplace of a set of values claiming universal validity and serving as the basic political reference for citizens and institutions throughout the world. The emergence and spread of such significant concepts as civilization, democracy, liberalism, parliamentarism, (human) rights, or tolerance, for example, are generally associated with modern European history.

Although the capacity to devise concepts with a degree of coherence, flexibility, and durability is common to all cultures, certain conceptual networks and patterns of conceptualization are defining features of the European culture. In this sense, Europeanness can be defined as a set both of concepts-including the very concept of Europe-shared by most Europeans, and of identifiable means of coining, articulating, and using them in the public sphere by virtue of common experience.

Nevertheless, the obvious similarities among the vocabularies employed in different parts of Europe, even the apparent terminological uniformity that has prevailed for decades in the European Union, conceal significant disparities, disagreements, and conceptual controversies, not only between languages, regions, or countries but also between speakers of the same language and between citizens of the same nation. As ordinary philosophy of language has shown, it is impossible to assign words permanent and unambiguous meanings, or to eliminate rhetoric from political life, by establishing a repertoire of supposedly transparent and univocal concepts.

The need to reconsider the conceptual vocabulary emanating from, or associated with, Europe has become more pressing in view of a crucial shift in contemporary scholarship. It entails a move away from twentieth-century teleological master narratives that assumed an inexorable drive towards rationalization, modernization, and progress, and away from such path determinacy, and the adoption instead of contingency, indeterminacy, fragility, and openness as the more realistic hallmarks of socio-political language and the concepts contained in such language.

Concepts have a history; but far from being a simple reflection of changing socio-political contexts, the conceptual matrices shape historical events and experiences. One of the main objectives of conceptual history is there- 
fore to shed light upon the complex relationships between social and political change and semantic innovation, both in the short and medium term and during longer historical periods.

The social production and diffusion of abstract notions has grown considerably in recent centuries with the advent of modernity. Concepts such as class, revolution and state, society, individual, communication, progress, crisis, citizenship, and many more have made their way, sometimes from very distant semantic fields, into ideological, scientific, and constitutional vocabularies, thus becoming irreplaceable, pivotal elements of political argument and action. Through the coinage and varied receptions of conceptual repertoires in European languages and countries, European cultures have gradually acquired their distinctive characteristics, while retaining and sharing a common substratum.

Surprisingly enough, the history of the processes of formation and development of such conceptual systems, inextricably woven into the construction of Europe, has so far not received the attention it deserves. With the specific aim of redressing this imbalance, a group of scholars from a number of European universities have set up the European Conceptual History Project (ECHP). This document presents the outlines of the project.

Our main aim is to study, from a comparative perspective, the evolution of a whole series of fundamental notions and cluster concepts linked to certain keywords in different languages and spatio-temporal contexts. Although most of the participants in the project find inspiration in well-known theoretical sources, such as the seminal work of R. Koselleck, conceptual history takes many different forms. In fact, "conceptual history" is a banner which brings together scholars from different academic traditions. They conduct research in the humanities and the social sciences from different methodological approaches, but share a common interest in language as a social phenomenon as well as some theoretical tenets.

The transdisciplinary nature of conceptual history places it at a crossroads of language, historiography, and politics. Moreover, it advocates a new kind of historiographical narrative which seeks to bring intellectual and cultural history closer to political and social history. A research program like this, which takes into account processes of intellectual transfer, reception, and interconnection all over the continent, is destined to become of considerable heuristic value to scholars from a wide range of social and humanist disciplines, from the history of political thought to philosophy, rhetoric, translation theory, historical lexicography, or political science.

Not least, the concept of Europe itself poses a serious challenge to scholarship on two levels. First, the historical evolution of the concept accumulated (and lost) meanings that have shaped current understandings. Second, diverse European perspectives on, and connotations of, the concept of Europe require 
to be navigated contemporaneously. Cultural, geographical, political, and linguistic dimensions of the idea of "Europe" have been created through transfers, translations, imitations, rejections, and adaptations.

All project members have done previous research in the historical-conceptual study of Europe's national spaces (Finland, France, Germany, the Netherlands, Romania, Spain, the UK...). What really differentiates the ECHP from other projects is the quest to transcend national boundaries, in order to study in a systematic manner, from a pan-European, comparative, and multilingual perspective, such an important but unexplored dimension of continental history.

Europeanization and globalization go hand in hand, given that the comparative view should in this case be applied both to the writing of internal, European history and to the extra-European horizon. Often by the crossing and hybridization of cultural elements from other continents or neighboring regions, in recent centuries Europe has projected outwards the language and concepts forged within its borders. This external projection has been, however, not a mechanical and one-directional process, but rather a kind of to-ing and fro-ing, in which asymmetrical conceptual relationships have often resulted in fusions, feedback, and creative reappropriations in the overseas territories subject to European influence. Thus, for example, the recodification of a handful of modernity concepts in North America and Latin America has generated a multiplication of modernities on both sides of the Atlantic, which only a fresh cross-cultural look freed of Eurocentric preconceptions will be able to comprehend in its entire complexity. These processes also include the assimilation of concepts now considered European, but whose origins lie elsewhere, and asymmetries of transfer and appropriation within Europe.

Such an ambitious comparative program requires teamwork, and that is why for some years a group of scholars has been involved in exploratory seminars and conferences on the conceptual constellations of European social and political vocabularies. They have provided the starting point of the editorial project.

The series European Conceptual Histories (ECH) will open with a general introductory volume, presenting the main lines and the theoretical framework of the endeavor, followed by another seven volumes dealing with cluster concepts: civilization, federalism, state and market, historical regions, liberalism, parliamentarism, and planning. The editorial board has commissioned the volumes to a number of editors who will coordinate the research of specialists from all over Europe.

The interdisciplinary and methodologically innovative nature of conceptual history makes the ECH a most interesting collection not only for historians, but also for political theorists, anthropologists, philosophers, sociologists, linguists, jurists, and political scientists, as well as for advanced students in the 
humanities, law, and the social sciences. Because of the variety and richness of the approaches, themes, and countries covered by the multilingual and interdisciplinary research teams, as well as the diverse geographical locations of the authors, the $\mathrm{ECH}$ series is aimed at a wide international readership.

The originality of the ECHP lies in a set of methodological options which deliberately stray from the paths trodden by customary historiography. Thus, rather than the usual emphasis upon unity and the consensual aspects of European identity, we are interested in shedding light on the plurality of debates and the ideological fracture lines regarding the interpretation of concepts. In fact, debates regarding the naming, meaning, scope, and normative color of concepts constantly appear in every sphere of society life-in morals and in science, in politics, and in the academic world-and such valuable institutions of modern European culture as freedom of expression, scientific societies, or parliaments respond to the need to channel these never-ending controversies and disagreements. Those tensions are embedded in languages that often hinder communication across boundaries and establish irreducible limits to the harmonization of vocabularies. As opposed to the traditional approaches in the history of ideas, which usually attribute excessive importance to a reduced canon of great thinkers, the project will also pay attention to everyday political settings, as reflected in sources like the press, parliamentary debates, pamphlets, etc.

Furthermore, without abandoning the interest in the flow and transfer of ideas, the project takes in other approaches, focused on the uses agents make of these ideas in particular historical contexts and with different objectives in mind. Our focus on the phenomena of cultural appropriation and conceptual adaptation will help overcome the old diffusionist models applied to intellectual history, and converge with the research agendas of cultural historians interested in the problems of translation, the circulation of texts, and other communicative practices; the outcome being a more complex and richer understanding of the political and intellectual experience than the one currently presented in most university textbooks. At the same time, to use Paul Ricoeur's notion of the surplus of meaning, agents also unconsciously and unintentionally transmit additional messages over which they have little control but that may be picked up by their recipients, and that influence the fluid and layered meanings of given concepts.

It is likely that this leap in scale, from national history to a supranational level of enquiry, will have significant consequences vis-à-vis our understanding of Europe. The comparative historical study of certain key notions will lead to questioning some long-standing perceptions. From the study of moments of semantic convergence and divergence, new narratives and alternative periodizations of European history will arise. From the spatial point of view, too, the attempt to map the evolution of a number of conceptual variants through- 
out Europe may reveal unexpected interregional connections, and even give rise to new units of analysis which do not necessarily coincide with the reductionist frameworks to which we are accustomed. They often misidentify "Europe" with either Western Europe or even with a few countries like France, Germany, and Great Britain.

It is reasonable to expect that the diffusion of the ECHP's results will improve the knowledge of historical variants of European identities, and hopefully will see its plurality reflected in new university curricula. Moreover, if, as some theorists argue, one of the main goals of current political philosophy should be the analysis of the mechanisms of innovation, obsolescence, and conceptual change, the ECHP can be remarkably useful in the design of new concepts. With these findings regarding the coining of new notions, social theorists will be better prepared to design those new intellectual tools so essential for dealing with the pressing demands of the knowledge society.

Finally, our commitment to a new European conceptual history, sensitive to both the internal complexity of our continent and to the developments and variants of political and social vocabularies beyond Europe, will enable us to establish a dialogue with other ongoing transnational projects, such as the Ibero-American Conceptual History Project (Iberconceptos) or the Project of Intercommunication of East Asian Basic Concepts. We will then be better equipped to explore modern history from a comparative, transnational perspective, a long but stimulating journey towards the gradual construction of a global history that one day may greatly enhance our knowledge of the world.

\section{Editorial Board of the European Conceptual Histories series}

Michael Freeden, Professor of Politics, University of Oxford, and Director of the Centre for Political Ideologies

Diana Mishkova, Professor in Modern and Contemporary History, Southeastern Centre for Advanced Study, Sofia

Javier Fernández Sebastián, Professor of History of Political Thought, University of the Basque Country, Bilbao

Willibald Steinmetz, Professor of Modern Political History, University of Bielefeld

Henrik Stenius, Research Director, Centre for Nordic Studies at the University of Helsinki

\section{Signatories}

Pim den Boer, Chair for the European Cultural History, University of Amsterdam 
Martin J. Burke, Professor, The Graduate Center, City University of New York Gonzalo Capellán, University of Cantabria, Santander

Dominic Eggel, Graduate Institute, Geneva

Anna Grzeskowiak-Krwawicz, Professor, Institute for Interdisciplinary

Studies, University of Warsaw

Irène Herrmann, Associate Professor of Modern History, University of

Fribourg

Pasi Ihalainen, Professor of General History, University of Jyväskylä

Jussi Kurunmäki, Researcher, Department of Poltical Science, Stockholm

University

André Liebich, Professor of International History and Politics, Graduate

Institute, Geneva

Carl Marklund, Researcher, CENS, University of Helsinki

Victor Neumann, Professor of History, West University of Timişoara

Kari Palonen, Director, Finnish Centre of Excellence in Political Thought

and Conceptual Change, University of Jyväskylä

Margrit Pernau, Senior Researcher, Max Planck Institute for Human

Development, Berlin

Pablo Sánchez León, University of the Basque Country, Bilbao

Alexander M. Semyonov, Associate Professor of History and Political Science,

St. Petersburg State University

Henriks Stenius, Research Director at CENS, University of Helsinki

Bo Stråth, Chair in Nordic, European, and World History, University of

Helsinki

Wyger Velema, Professor, Department of History, University of Amsterdam 